\title{
An Improved Method for the Identification of Soybean Resistance to Phytophthora sojae Applied to Germplasm Resources from the Huanghuaihai and Dongbei Regions of China
}

\author{
Jin Yang, Wenwu Ye, Xiaomen Wang, Linrong Ren, Yan Yao, Xiaoli Wang, Yan Wang, Suomeng Dong, Xiaobo Zheng, \\ and Yuanchao Wang
}

Department of Plant Pathology, Nanjing Agricultural University, and Key Laboratory of Integrated Management of Crop Diseases and Pests, Ministry of Education, Nanjing, Jiangsu 210095, China

\begin{abstract}
Phytophthora root and stem rot (PRR) caused by Phytophthora sojae is a destructive disease afflicting soybean. The use of resistant cultivars is the most effective method to combat PRR. PRR resistance was assessed in 223 soybean cultivars from Huanghuaihai and Dongbei, major soybean-producing regions in east central and northeastern China. To evaluate levels of soybean resistance to $P$. sojae, we used eight representative $P$. sojae isolates and a modified etiolated hypocotyl-slit inoculation method. The cultivars Wandou21020, Xu9302-A, Kedou10, and Lidi055

highly virulent PsJS2 isolate, which is consistent with the reactions of the Chapman differential line that carries Rps $3 a$. The diverse reaction patterns seen in germplasm from different regions (provinces/ cities) in this study reflect the variety of PRR-resistant soybean sources in China. Our research indicates that sources of $P$. sojae resistance are present in the major soybean production areas of China. This study provides useful information for soybean breeding programs.
\end{abstract} showed resistance to all eight isolates; 14 cultivars showed intermediate resistance to all eight $P$. sojae isolates, and 53 cultivars were resistant to seven isolates. Thirty-three cultivars $(15 \%)$ were susceptible only to the
Keywords: improved method, Phytophthora sojae, resistance genes, soybean germplasm resources
Phytophthora root and stem rot (PRR), caused by Phytophthora sojae (M. J. Kaufmann \& J. W. Gerdemann), is a destructive disease in soybean, causing approximately $\$ 1$ to 2 billion in losses worldwide annually (Tyler 2007). P. sojae infects soybean via chemotaxis of zoospores that are attracted to the isoflavones daidzein and genistein, which are secreted by soybean roots throughout the growing season (Morris and Ward 1992). Infection results in seedling damping off, root and stem rot, leaf yellowing and wilting, and sometimes death of adult soybean plants (Schmitthenner 1985). This disease imposes serious limitations on soybean production, causing yield losses of 4 to $100 \%$ (Sugimoto et al. 2012). In some years, PRR was the second most important yield-limiting disease of soybean in the northern central United States (Doupnik 1993). The disease was first reported in 1955 (Kaufmann and Gerdemann 1958); since that time, at least 55 races have been reported (Grau et al. 2004; Jackson et al. 2004; Leitz et al. 2000; Morgan and Hartwig 1965). The reported 223 pathotypes and complex pathogenic variation of $P$. sojae (Dorrance et al. 2016) make it difficult to control. $P$. sojae is widespread in China and has been reported in Heilongjiang, Jiangsu, Anhui, Fujian, Henan, Shandong, Xinjiang, and Sichuan provinces (Chen et al. 2004, 2016; Zhang et al. 2010).

Methods to control the disease include resistant and tolerant cultivars, fungicide application, and biological and cultural methods (Schmitthenner 1985). Fungicide seed treatment of cultivars with

\section{${ }^{\dagger}$ Corresponding author: Y.C. Wang; wangyc@njau.edu.cn}

Funding: This work was supported by grants to Y. C. Wang from the China Agriculture Research System (CARS-004-PS14) and the Special Fund for Agro-Scientific Research in the Public Interest of China (201303018).

*The $\boldsymbol{e}$-Xtra logo stands for "electronic extra" and indicates that one supplementary figure and four supplementary tables are published online.

The author(s) declare no conflict of interest.

Accepted for publication 23 August 2019

(C) 2020 The American Phytopathological Society partial resistance has been beneficial in controlling PRR (Dorrance and McClure 2001; Dorrance and Schmitthenner 2000; Dorrance et al. 2009). The use of resistant soybean cultivars is the primary and most effective method to combat the disease (Sugimoto et al. 2012), and numerous sources of resistance have been identified (Jiang et al. 2017; Kyle et al. 1998; Lohnes et al. 1996; Slaminko et al. 2010).

To date, at least 27 single genes conferring resistance to $P$. sojae (Rps genes) have been identified, including Rpsla, Rps1b, Rpslc, Rps1d, Rps1k, Rps2, Rps3a, Rps3b, Rps3c, Rps4, Rps5, Rps6, Rps7, Rps8, Rps9, Rps10, Rps11, Rps12, RpsYD25, RpsYu25, RpsYD29, RpsUN1, RpsJS, RpsSN10, RpsYB30, RpsWaseshiroge, and RpsZS18 (Fan et al. 2009; Lin et al. 2013; Ping et al. 2016; Sahoo et al. 2017; Sandhu et al. 2005; Sun et al. 2014; Wu et al. 2011; Yao et al. 2010; Yu et al. 2010; Zhang et al. 2013; Zhu et al. 2007). Rpsla was the first Rps gene widely deployed in the United States (Schmitthenner 1985). During the past several decades, Rps $1 k$ has become the most stable and widely used gene in the major soybeanproducing regions of the United States (Gao et al. 2005). Rpsld and Rps $1 k$ were the most effective resistance genes in Japan in 2010 (Sugimoto et al. 2012). Nevertheless, the eventual evolution of new strains of $P$. sojae will likely confer the ability to overcome these single Rps genes. Moreover, persistent use of stable soybean cultivars with partial resistance is appropriate for yield production (Dorrance and McClure 2001; Sugimoto et al. 2012). On average, single Rps genes have been found to be effective for 8 to 15 years (Schmitthenner 1985). It is important to evaluate soybean cultivar resistance to $P$. sojae to control this disease.

Lohnes et al. (1996) examined the distribution of Phytophthoraresistant soybean accessions from central China and classified their reactions to races $1,3,7$, and 25 of $P$. sojae. They observed resistance to be more common in accessions from the eastern provinces of central China, especially Anhui and Jiangsu, where the use of resistant soybean lines was most frequent. Kyle et al. (1998) investigated the distribution and diversity of resistant soybean in southern China, evaluating the resistance of 628 accessions to races $1,3,4,5,7,10$, $12,17,20$, and 25 of $P$. sojae using a hypocotyl inoculation technique. Most of the accessions were resistant to eight or more of the 10 races from the provinces of Hubei, Jiangsu, and Sichuan in 
southern China. Zhang et al. (2010) evaluated 62 soybean cultivars from Heilongjiang province in northeastern China for resistance to eight races, and they found that 44 cultivars were resistant to at least one race. A large number of studies have shown extensive amounts of resistant soybean germplasm to be present in southern, central, and northeastern China (Chen et al. 2016; Kyle et al. 1998; Zhang et al. 2010).

Huanghuaihai and Dongbei are regions in east central and northeastern China, which are major areas of soybean production (Yin et al. 2017). To evaluate the levels of soybean resistance to $P$. sojae, we tested 223 soybean cultivars for their responses to eight representative $P$. sojae isolates following inoculation using a modified etiolated hypocotyl-slit inoculation method.

\section{Materials and Methods}

Soybean cultivars. The seeds of soybean cultivars from at least 12 provinces or cities of China (Fig. 1) were provided by Professor Shi Sun at the Chinese Academy of Agricultural Sciences (CAAS). Detailed information about these seeds is provided in Supplementary Table S1. The soybean germplasm resources used in this study are new cultivars developed by breeding programs at academies of agricultural sciences in different provinces. It was unknown whether these cultivars were Phytophthora resistant. Seeds from a set of 14 differential soybean lines were provided by Professor Han Xing at Nanjing Agricultural University. The development of the differentials is shown in Table 1. We used 14 differential soybean lines, each carrying a single Rps gene, to confirm the pathotypes of $P$. sojae, produce standard reaction types, and validate the modified inoculation method (Supplementary Table S2). The differentials were Harlon (Rpsla), Harosoy 13XX (Rpslb), Williams 79 (Rpslc), PI 103091 (Rps1d), Williams 82 (Rps1k), L76-1988 (Rps2), Chapman (Rps3a), PRX146-36 (Rps3b), PRX145-48 (Rps3c), L85-2352 (Rps4), L853059 (Rps5), Harosoy 62XX (Rps6), Harosoy (Rps7), and PI 399073 (Rps8). Williams, which has none of the 14 Rps genes, was used as a susceptible control (Dorrance et al. 2004; McBlain et al. 1991), and Hefeng 47 was used as a second control from China (resistant to Ps1, Ps3, and Ps5; susceptible to Ps4, Ps41-1, PsMC1, PsJS2, and PsUSAR2 (Table 1).

$P$. sojae isolates and cultivation. The eight representative $P$. sojae isolates were collected and provided by Professor Zhendong Zhu (CAAS), including isolates representing Ps1, Ps3, Ps4, and Ps5 originating from Heilongjiang province (Zhang et al. 2010); PsUSAR2 from the United States (provided by A. F. Schmitthenner); PsMC1 from Anhui province; PsJS2 from Jiangsu province; and Ps41-1 from Heilongjiang province (Zhang et al. 2014). The pathotypes of the eight isolates were confirmed using the hypocotyl-slit inoculation method (Dorrance et al. 2008) on the 14 differential soybean lines carrying a single $R p s$ gene. The $P$. sojae isolates were stored in $10 \%$ V8 juice agar medium at $12^{\circ} \mathrm{C}$ in the dark.

Characterization of soybean resistance. Etiolated seedlings were inoculated using a modified etiolated hypocotyl inoculation

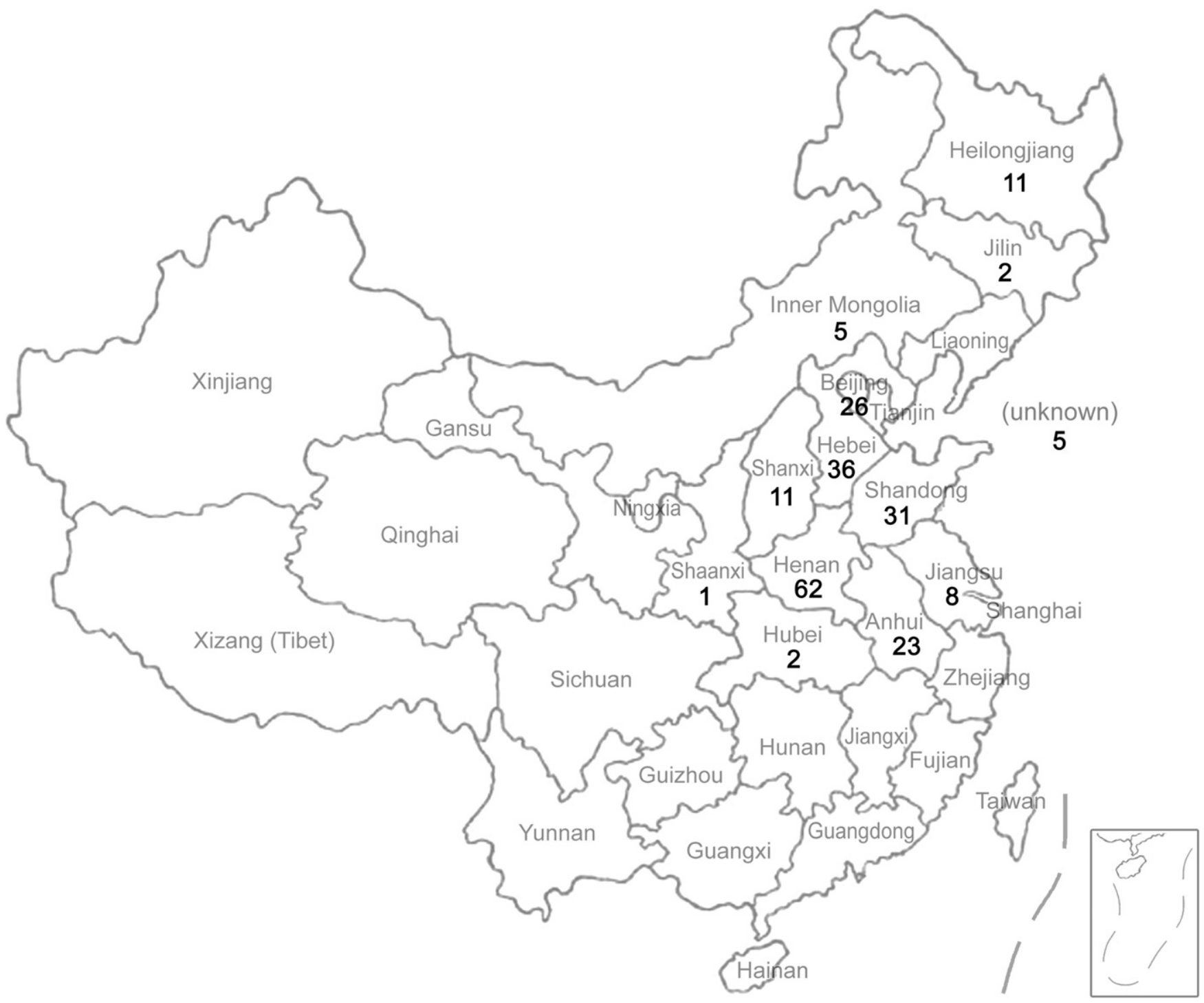

Fig. 1. The origin of soybean cultivar seeds in China. The numbers of soybean cultivars for each province (city) are also shown. 
method. Etiolated soybean seedlings were grown in vermiculite at $25^{\circ} \mathrm{C}$ during the day $(14 \mathrm{~h})$ and night $(10 \mathrm{~h})$ for 4 days, after which the vermiculite was washed off for disease assays. A $15-\mathrm{mm}$ cork borer was then used to cut material from the growing edge of 5- to 7-day-old $P$. sojae cultures. A 15-mm-diameter agar plug was placed mycelial side down to the hypocotyl where a slit had been slightly punctured with a knife tip, 1 to $2 \mathrm{~cm}$ below the cotyledon. A 15mm-diameter inoculum-free $10 \%$ V8 agar plug was used as a noninoculated control (Supplementary Fig. S1). We then wrapped the inoculation site in absorbent paper $\left(\sim 10 \mathrm{~cm}^{2}\right)$ saturated with sterilized water. Five plants of each soybean cultivar were inoculated with each $P$. sojae isolate and then wrapped with tin foil. The inoculated plants were placed in the greenhouse at $25^{\circ} \mathrm{C}$, with $14 \mathrm{~h}$ of light and $10 \mathrm{~h}$ of darkness. Every assay was repeated twice for a total of 10 plants per cultivar per isolate.

The resistance phenotype was determined at 4 days postinoculation on the basis of the reaction of five plants. A cultivar was characterized as resistant $(\mathrm{R})$ when more than three of five plants were similar to the noninoculated control or exhibited soft red-brown patches only at the inoculated sites and had normal root growth. If the water soaked or red-brown patch had expanded from the inoculated sites on more than three plants and the roots were barely developed, the cultivar was classified as susceptible (S). If the disease lesion appeared only at the inoculation site (whether or not it encompassed the stem) and the roots were normal compared with the control in more than three plants, or if there were two healthy and three diseased plants or two diseased and three healthy plants, then the cultivar was identified as having intermediate resistance (IR). If there were differences between the two assays, we repeated the assay a third time and recorded the response shown in two of the three assays. Assays producing intermediate resistance reactions were repeated until the result was stable (Supplementary Table S3, detailed results for partial cultivars). Intermediate resistance was classified as "resistance' in the reaction pattern analysis (Kyle et al. 1998).

\section{Results}

Pathotypes of the representative $P$. sojae isolates. The identified pathotypes of the $P$. sojae isolates are shown in Figure 2A. Among these isolates, PsJS2 overcame all 14 Rps genes and contained no known avirulence $(A v r)$ genes (pathotype: 1a, 1b, 1c, 1d, 1k, 2, 3a, 3b, 3c, 4, 5, 6, 7, and 8), whereas Ps1 (pathotype: 7), Ps3 (1a, 7), and Ps4 (1a, 1c, 7) were comparatively weaker, overcoming one, two, and three Rps genes, respectively.

The reaction types of the 14 differential soybean lines inoculated with eight representative $P$. sojae isolates are shown in Table 1 . According to the reaction types, lines containing the Rpsla, Rpslb, Rps1c, Rps1d, Rps3a, and Rps6 genes were distinguishable, whereas those with the Rps1k, Rps2, Rps3b, Rps3c, Rps4, Rps5, Rps7, and $R p s 8$ genes were not. Thus, the eight representative $P$. sojae isolates can be used to identify hosts with the Rpsla, Rpslb, Rpslc, Rpsld, $R p s 3 a$, and Rps6 genes and to identify cultivars that might have novel Rps genes.

Resistance of the soybean germplasm resources. We found that $>80 \%$ of the tested soybean cultivars were simultaneously resistant to the isolates Ps1, Ps3, and Ps5 (82, 81, and 88\%, respectively). Among the isolates, such as PsUSAR2 (pathotype: 1b, 2, 3c, 5, 7), Ps41-1 (1a, 1d, 2, 3b, 3c, 5, 7, 8), and PsMC1 (1a, 1c, 1k, 2, 3b, $3 \mathrm{c}, 4,5,6,7,8)$, the proportions of resistant cultivars were reduced to 16,40 , and $36 \%$, respectively. Only $5 \%$ of soybean cultivars exhibited resistance to isolate PsJS2. In addition, $16 \%$ of the 223 cultivars showed intermediate resistance to Ps1, and 14, 35, 10, 24, 16, 33 , and $18 \%$ showed intermediate resistance to Ps3, Ps4, Ps5, PsUSAR2, Ps41-1, PsMC1, and PsJS2, respectively (Fig. 2A).

All 223 cultivars showed intermediate resistance to at least two isolates, and $>56 \%$ were resistant to six or more isolates. Wandou21020, Xu9302-A, Kedou10, and Lidi055 were resistant to all eight isolates. Fourteen cultivars showed intermediate resistance to eight isolates, and 54 were resistant to seven isolates (Fig. 2B); thus, many of the resistant cultivars showed only intermediate resistance. Average numbers of soybean-resistant $P$. sojae isolates were similar among individual provinces or cities, ranging between five and six isolates (Fig. 2C), indicating that resistant cultivars are abundant in all of these regions. Most resistant soybean cultivars were resistant to four isolates (Fig. 2B and C). Thus, overall, the examined soybean germplasm resources exhibited a broad spectrum of resistance to $P$. sojae.

Reaction patterns and resistance gene postulation. A comparison of the reaction patterns of each tested cultivar with those of the differential lines was used to postulate the Rps gene complement. The 223 cultivars developed 35 different reaction patterns (Fig. 3). The most common of these, occurring in 34 cultivars (15\%), was RRRRRRRS, indicating resistance to $P$. sojae isolates Ps1, Ps3, Ps4, Ps5, PsUSAR2, Ps41-1, and PsMC1 but susceptibility to PsJS2. This reaction pattern is consistent with that of the Chapman differential line, which carries Rps $3 a$. The second most common reaction pattern (RRRRSRRS) was observed in 22 soybean cultivars (10\%), which were postulated to have Rps $1 b$. An RRRRRSRS pattern was consistent with Rps1d, which was observed in 10 soybean cultivars. The RRRRSSSS reaction pattern, which was consistent with that of differentials carrying $R p s 2, R p s 3 c$, Rps 5 , or a combination of these, was observed in 11 cultivars. Five cultivars with an RRRRRRSS reaction pattern and three with RRRRRSSS were postulated to have $R p s 1 k$ and/or Rps4, and Rps $3 b$ and/or Rps8, respectively. Resistance gene complements could not be deduced for 30 other reaction types,

Table 1. Reactions of 14 differential soybean lines inoculated with eight representative Phytophthora sojae isolates

\begin{tabular}{|c|c|c|c|c|c|c|c|c|c|c|c|}
\hline \multirow[b]{2}{*}{ Soybean line ${ }^{\mathbf{a}}$} & \multirow[b]{2}{*}{ Rps gene } & \multicolumn{8}{|c|}{$P$. sojae isolates $^{\mathbf{b}}$} & \multirow[b]{2}{*}{ Reaction pattern } & \multirow[b]{2}{*}{ Reference for differential line origin } \\
\hline & & $\overline{\text { Ps1 }}$ & Ps3 & Ps4 & Ps5 & PsUSAR2 & Ps41-1 & PsMC1 & $\overline{\text { PsJS2 }}$ & & \\
\hline Harlon & Rpsla & $\mathrm{R}$ & $\mathrm{S}$ & $\mathrm{S}$ & $\mathrm{S}$ & $\mathrm{R}$ & $\mathrm{S}$ & $\mathrm{S}$ & $\mathrm{S}$ & RSSSRSSS & Schmitthenner et al. (1994) \\
\hline Harosoy $13 \mathrm{XX}$ & Rpslb & $\mathrm{R}$ & $\mathrm{R}$ & $\mathrm{R}$ & $\mathrm{R}$ & $\mathrm{S}$ & $\mathrm{R}$ & $\mathrm{R}$ & $\mathrm{S}$ & RRRRSRRS & Buzzell et al. (1987) \\
\hline Williams 79 & Rps1c & $\mathrm{R}$ & $\mathrm{R}$ & $S$ & $\mathrm{~S}$ & $\mathrm{R}$ & $\mathrm{R}$ & $S$ & $S$ & RRSSRRSS & Moots et al. (1983) \\
\hline PI 103091 & Rpsld & $\mathrm{R}$ & $\mathrm{R}$ & $\mathrm{R}$ & $\mathrm{R}$ & $\mathrm{R}$ & $S$ & $\mathrm{R}$ & $S$ & RRRRRSRS & Buzzell and Anderson (1992) \\
\hline Williams 82 & Rpslk & $\mathrm{R}$ & $\mathrm{R}$ & $\mathrm{R}$ & $\mathrm{R}$ & $\mathrm{R}$ & $\mathrm{R}$ & $\mathrm{S}$ & $\mathrm{S}$ & RRRRRRSS & Moots et al. (1983) \\
\hline L76-1988 & Rps2 & $\mathrm{R}$ & $\mathrm{R}$ & $\mathrm{R}$ & $\mathrm{R}$ & $\mathrm{S}$ & $\mathrm{S}$ & $\mathrm{S}$ & $\mathrm{S}$ & RRRRSSSS & Kilen et al. (1974) \\
\hline Chapman & Rps3a & $\mathrm{R}$ & $\mathrm{R}$ & $\mathrm{R}$ & $\mathrm{R}$ & $\mathrm{R}$ & $\mathrm{R}$ & $\mathrm{R}$ & $\mathrm{S}$ & RRRRRRRS & McBlain et al. (1991) \\
\hline PRX-146-36 & $R p s 3 b$ & $\mathrm{R}$ & $\mathrm{R}$ & $\mathrm{R}$ & $\mathrm{R}$ & $\mathrm{R}$ & $\mathrm{S}$ & $\mathrm{S}$ & $\mathrm{S}$ & RRRRRSSS & Buzzell et al. (1987) \\
\hline PRX-145-48 & Rps $3 c$ & $\mathrm{R}$ & $\mathrm{R}$ & $\mathrm{R}$ & $\mathrm{R}$ & S & $S$ & S & $S$ & RRRRSSSS & Dorrance et al. (2004) \\
\hline L85-2352 & Rps 4 & $\mathrm{R}$ & $\mathrm{R}$ & $\mathrm{R}$ & $\mathrm{R}$ & $\mathrm{R}$ & $\mathrm{R}$ & $S$ & $S$ & RRRRRRSS & Athow et al. (1980) \\
\hline L85-3059 & Rps5 & $\mathrm{R}$ & $\mathrm{R}$ & $\mathrm{R}$ & $\mathrm{R}$ & S & S & S & S & RRRRSSSS & Buzzell and Anderson (1981) \\
\hline Harosoy $62 \mathrm{XX}$ & Rps6 & $\mathrm{R}$ & $\mathrm{R}$ & $\mathrm{R}$ & $\mathrm{S}$ & $\mathrm{R}$ & $\mathrm{R}$ & $\mathrm{S}$ & $\mathrm{S}$ & RRRSRRSS & Buzzell et al. (1987) \\
\hline Harosoy & Rps7 & $S$ & S & S & $S$ & S & $S$ & S & $\mathrm{S}$ & SSSSSSSS & Anderson and Buzzell (1992) \\
\hline PI 399073 & Rps8 & $\mathrm{R}$ & $\mathrm{R}$ & $\mathrm{R}$ & $\mathrm{R}$ & $\mathrm{R}$ & $S$ & $S$ & S & RRRRRSSS & Burnham et al. (2003) \\
\hline Williams & rps & $\mathrm{S}$ & $\mathrm{S}$ & $\mathrm{S}$ & $\mathrm{S}$ & $\mathrm{S}$ & $\mathrm{S}$ & $\mathrm{S}$ & $\mathrm{S}$ & SSSSSSSS & Wagner and Bernard (1991) \\
\hline Hefeng 47 & rps & $\mathrm{R}$ & $\mathrm{R}$ & $\mathrm{S}$ & $\mathrm{R}$ & $\mathrm{S}$ & $\mathrm{S}$ & $\mathrm{S}$ & $\mathrm{S}$ & RRSRSSSS & \\
\hline
\end{tabular}

\footnotetext{
a The genetic background and the source of each Rps gene were obtained from Dorrance et al. (2004) and McBlain et al. (1991).
}

${ }^{\mathrm{b}} \mathrm{R}=$ resistant and $\mathrm{S}=$ susceptible. 
which may indicate new Rps genes, a combination of novel Rps genes, or a combination of novel and known Rps genes.

Some reaction patterns were more common in soybean cultivars from particular provinces or cities. For example, $21 \%$ of cultivars from Henan province had a RRRRSRRS pattern (postulated to have Rps 1 b), which was significantly $>10 \%$ observed among all tested cultivars. In addition, 22, 22, and $17 \%$ of cultivars from the Dongbei region (Heilongjiang, Jilin, and Inner Mongolia) had the patterns RRRRSSRS, RRRRSSSS (postulated to have Rps2, Rps $3 c$, and/or Rps5), and RRRRSSRR, respectively; $10 \%$ of those from Shandong province had RRSRSSRS, $8 \%$ of those from Heibei province had RSSRSSSS, and $17 \%$ of those from Shanxi and Shaanxi provinces had RRSRRRRS (Fig. 3). These results indicate that the examined soybean germplasm resources had diverse reaction patterns of $P$. sojae resistance.

\section{Discussion}

Many surveys have been conducted over the past few decades to identify soybean resistance to $P$. sojae; however, the $P$. sojae isolates used in these studies were inconsistent. Until recently, eight $P$. sojae isolates were used to represent the major pathotypes and are currently used to identify soybean resistance in China ( $\mathrm{Li}$ et al. 2017). However, it appears that these isolates are not representative of all pathotypes occurring in China.
Jiang et al. (2017) modified a common $P$. sojae resistance identification assay to make it simpler and more cost-effective (Dorrance et al. 2008; Schmitthenner et al. 1994; Stewart and Robertson 2012). In that type of assay, $P$. sojae inoculum was mixed into soil and resistance was evaluated by the survival rate (percentage) of soybean seedlings (mixing agar homogenate containing $P$. sojae into the soil [MAPS]). This method was then applied to evaluate $P$. sojae resistance in soybean mini core collections, revealing wide variation in resistance among individual varieties (Jiang et al. 2017). However, the MAPS method requires longer than 3 weeks from the growth of $P$. sojae to the scoring of seedling survival rates. ArsenaultLabrecque et al. (2018) developed a simple hydroponic assay to study resistance in soybean. However, differences in zoospore production among individual isolates have caused difficulties in mass resistance identification using this method. We assessed $P$. sojae resistance in soybean by modifying the etiolated hypocotyl-slit inoculation method of Dorrance et al. (2004) and Dong et al. (2009), using absorbent paper and tin foil wrap to maintain humidity and exclude light. A previous method described by Dorrance et al. (2004) used absorbent paper to wrap all etiolated seedlings of each cultivar, whereas our method used absorbent paper to wrap every plant from each cultivar to ensure that the mycelium touched hypocotyls and the tin foil to segregate each cultivar from others and maintain the darkness condition of $P$. sojae. Dong et al. (2009) used
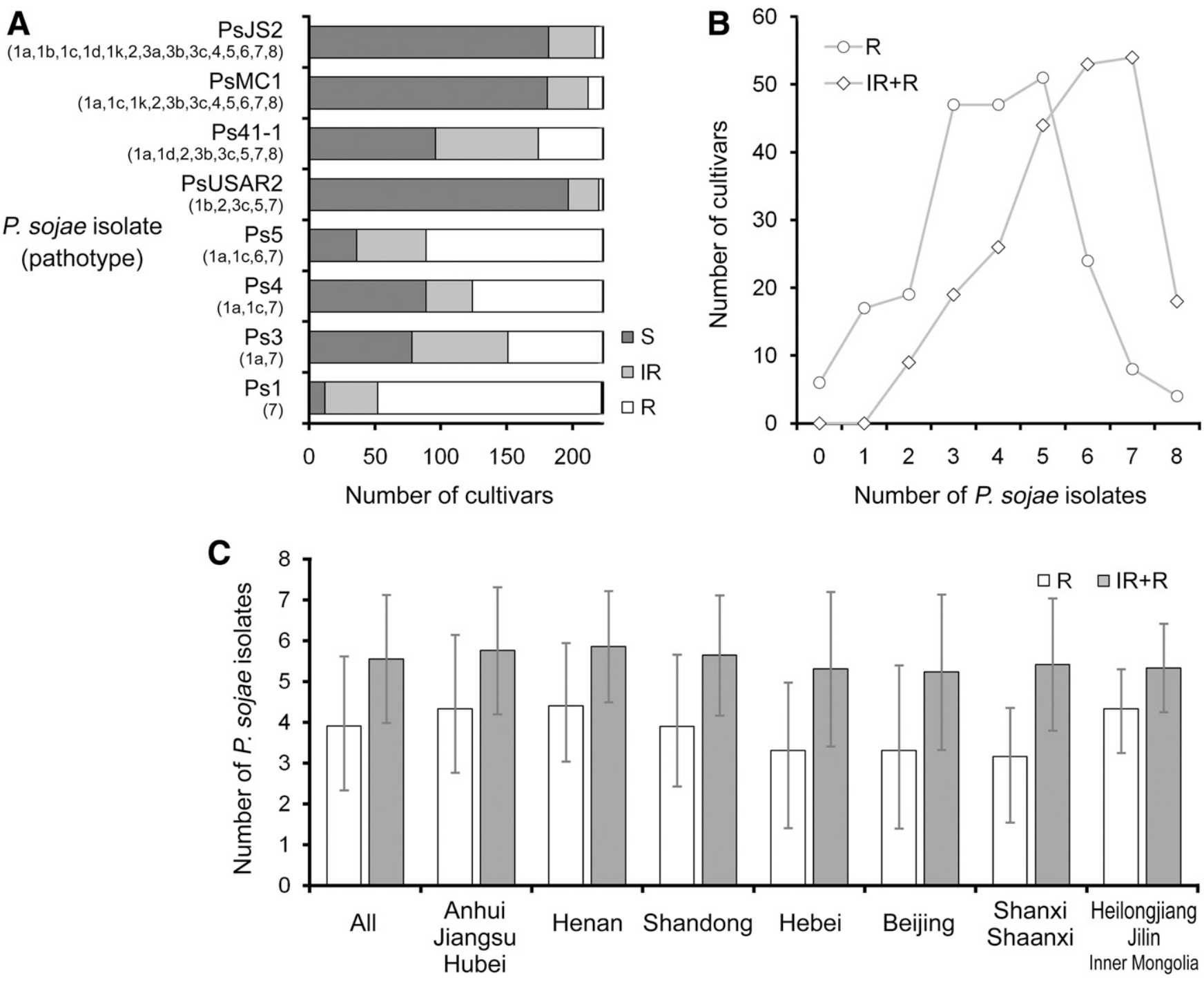

Fig. 2. Characterization of Phytophthora sojae resistance for the 223 soybean cultivars. A, The number of resistance soybean cultivars on different $P$. sojae isolates. B, The number of resistance soybean cultivars on different numbers of $P$. sojae isolates in $\mathrm{R}$ and $\mathrm{IR}+\mathrm{R}$ levels, respectively. C, The average numbers of soybean-resistant $P$. sojae isolates among the provinces (cities). $\mathrm{S}=$ susceptible, $\mathrm{IR}=$ intermediate resistance, and $\mathrm{R}=$ resistance. 
plastic bags to maintain humidity, which requires a large space; our method greatly conserved space and time and is thus well suited for large-scale evaluation of $P$. sojae resistance. The responses of 14 differential lines to eight isolates using our modified method were consistent with results obtained using the hypocotyl inoculation method (Dorrance et al. 2008). Our method attained $>90 \%$ repeatability, such that it can be used to identify resistance patterns in soybean. We repeated our experiments on several cultivars using the method described by Jiang et al. (2017), and we observed very similar responses $(92 \%)$ compared with those obtained by our etiolated hypocotyl inoculation method (Supplementary Table S4).

The eight differential isolates allowed us to postulate the involvement of single genes Rpsla, Rps1b, Rps1c, Rps1d, Rps3a, and Rps6, but not other specific $R p s$ genes, according to the reaction types. Reactions in the differential lines L76-1988 (Rps2), PRX145-48 (Rps3c), and L85-3059 (Rps5) were so similar that it was impossible to identify the relevant $R p s$ genes accurately. Similarly, we were not able to predict the involvement of specific $R p s$ genes in cultivars with the RRRRRRSS (Rpslk or Rps4) or RRRRRSSS (Rps $3 b$ or $R p s 8$ ) reaction patterns. There were no reaction types consistent with the

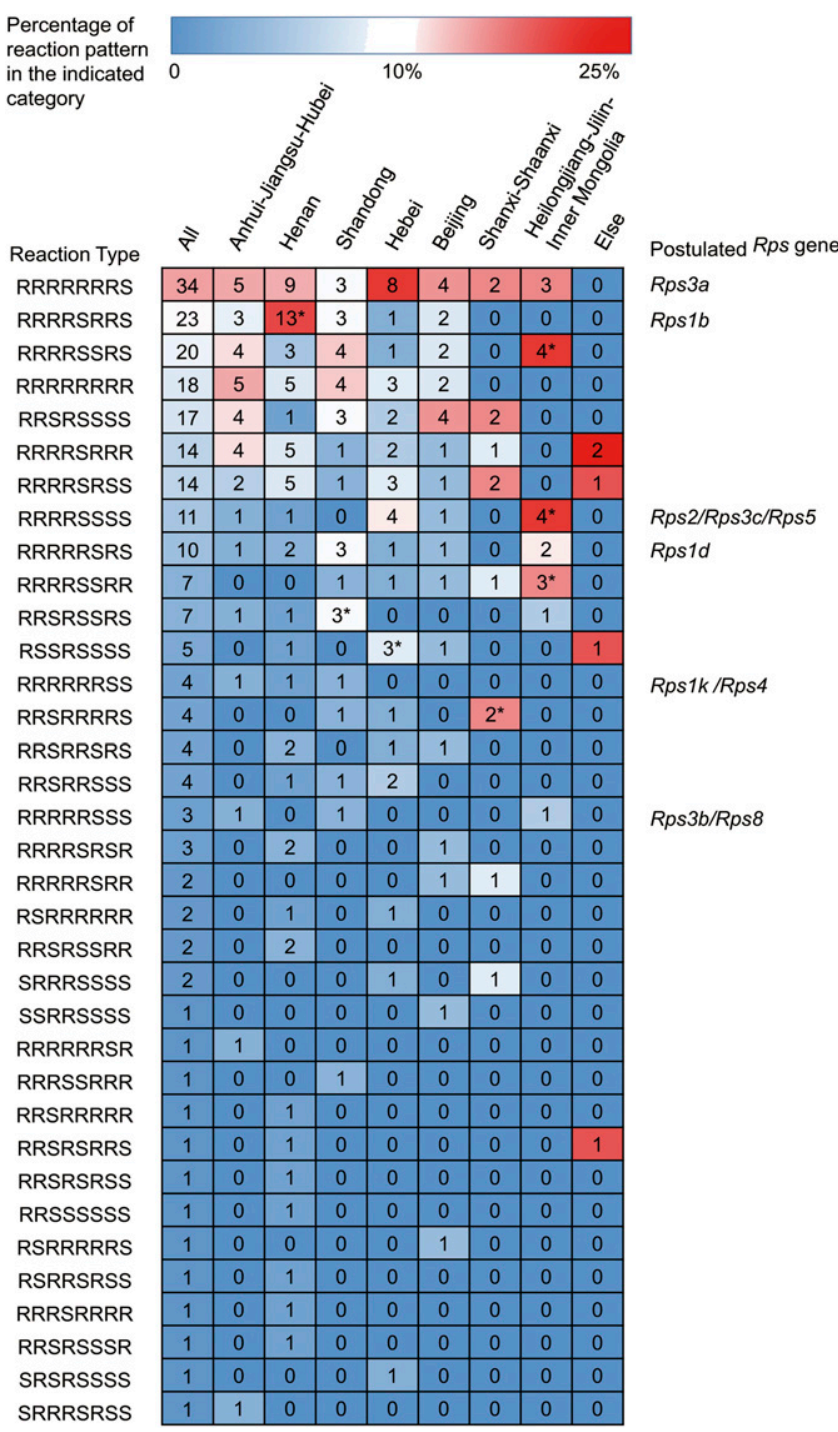

Fig. 3. Reaction patterns of the 233 soybean cultivars. Reaction patterns followed the isolate order Ps1, Ps3, Ps4, Ps5, PsUSAR2, Ps41-1, PsMC1, and PsJS2. The numbers of cultivars are shown, and the percentage of the indicated reaction pattern in the indicated provinces (cities) is displayed as the background in the heatmap. Asterisks indicate a significantly higher percentage of the reaction pattern in the indicated provinces (cities), compared with that in all 233 soybean cultivars, using an hypergeometric test $(P<0.05)$. differential lines containing the Rpsla, Rpslc, and Rps6 genes, indicating that these three Rps genes were not distributed among the soybean germplasm resources. Only five soybean cultivars were postulated to contain Rps $1 k$ and/or Rps4, indicating that the distributions of Rpsla, Rpslc, and Rpslk were not extensive in this region. These results were consistent with those of Tang et al. (2010). Zhu et al. (2006) evaluated 120 cultivars from 11 provinces by challenging them with 10 isolates of $P$. sojae, and they hypothesized that $11 \mathrm{cul}-$ tivars contained known Rps genes. Zhang et al. (2014) identified 34 cultivars from Henan province, inoculated these with $26 P$. sojae pathotypes, and postulated that Rps $3 a$ and/or Rps 5 were present in cultivars Zhoudou 17 and Zheng77249. However, we determined that Rps $1 b$ and Rps $3 a$ were widespread in Henan province and other regions. Among the 35 reaction types produced by the 223 soybean cultivars, 29 were not consistent with any single reaction type of a differential line; thus, they may have involved several resistance genes or novel Rps genes.

To place minimal selection pressure on $P$. sojae populations, it is recommended to deploy cultivars with partial resistance, which is predicted to be more durable, and many soybean cultivars exhibit partial resistance (Abeysekara et al. 2016; Schneider et al. 2016). Although the deployment of $R p s$ genes induced high selection pressures on $P$. sojae populations, causing the evolution of populations that overcome the Rps gene resistance, resistance mediated by major Rps genes is a highly effective and complete resistance in field production (Dorrance et al. 2003).

Most of the examined cultivars were resistant to five to six $P$. sojae isolates, revealing a broad spectrum of resistance to $P$. sojae. In addition, the spectrum of resistance was likely associated with the origins of the cultivars. For example, cultivars resistant to all eight isolates came mainly from Anhui-Jiangsu-Hubei and Shandong, whereas none were from the Shanxi-Shaanxi or Dongbei regions (Heilongjiang-Jilin-Inner Mongolia; Fig. 3). The soybean cultivars showed diverse reaction patterns in $P$. sojae resistance among cultivar origins. We found that Rps $1 b$ was not effective in Henan, Anhui, Shandong, or Jiangsu provinces, and Rps $3 a$ was effective in Heilongjiang, Shandong, and Henan provinces (unpublished data). In this survey, most cultivars from Henan province were postulated to contain Rps1b. Some cultivars from Heilongjiang, Shandong, and Henan provinces contained Rps $3 a$, so these cultivars could be deployed in Heilongjiang, Shandong, and Henan. Wandou21020, Xu9302-A, Kedou10, and Lidi055, which were resistant to all eight isolates, may serve as new resources for $P$. sojae resistance. Our evaluation of the resistance of these cultivars in China will allow resistant cultivars to be bred according to specific $P$. sojae pathotypes in different areas. Thus, the abundant germplasm resources found to be resistant to $P$. sojae will provide source materials for soybean breeding programs and reduce pesticide use in field production.

\section{Acknowledgments}

We thank Professor Zhendong Zhu (CAAS) for providing the eight $P$. sojae isolates, Professor Shi Sun (CAAS) for supplying soybean germplasm resources, and Professor Han Xing (Nanjing Agricultural University) for supplying seeds of soybean differential lines. We thank all of the breeders who developed and bred the differential cultivars

\section{Literature Cited}

Abeysekara, N. S., Matthiesen, R. L., Cianzio, S. R., Bhattacharyya, M. K., and Robertson, A. E. 2016. Novel sources of partial resistance against in soybean PI 399036. Crop Sci. 56:2322-2335.

Anderson, T. R., and Buzzell, R. I. 1992. Inheritance and linkage of the Rps7 gene for resistance to Phytophthora rot of soybean. Plant Dis. 76:958-959.

Arsenault-Labrecque, G., Sonah, H., Lebreton, A., Labbe, C., Marchand, G., Xue, A., Belzile, F., Knaus, B. J., Grunwald, N. J., and Belanger, R. R. 2018. Stable predictive markers for Phytophthora sojae avirulence genes that impair infection of soybean uncovered by whole genome sequencing of 31 isolates. BMC Biol. 16:80.

Athow, K. L., Laviolette, F. A., Mueller, E. H., and Wilcox, J. R. 1980. A new major gene for resistance to Phytophthora megasperma var. sojae in soybean. Phytopathology 70:977-980.

Burnham, K. D., Dorrance, A. E., VanToai, T. T., and St. Martin, S. K. 2003. Quantitative trait loci for partial resistance to Phytophthora sojae in soybean Crop Sci. 43:1610-1617. 
Buzzell, R. I., and Anderson, T. R. 1981. Another major gene for resistance to Phytophthora megasperma var. sojae in soybean. Soybean Genet. Newsl. 18: 30-33.

Buzzell, R. I., and Anderson, T. R. 1992. Inheritance and race reaction of a new soybean Rps 1 allele. Plant Dis. 76:600-601.

Buzzell, R. I., Anderson, T. R., and Rennie, B. D. 1987. Harosoy Rps isolines. Soybean Genet. Newsl. 14:1-4.

Chen, Q. H., Weng, Q. Y., Wang, Y. C., and Zheng, X. B. 2004. Identification and sequencing of ribosomal DNA-ITS of Phytophthora sojae in Fujian. Acta Phytopathol. Sin. 34:112-116.

Chen, S., Zhang, T., Xiao, L., Wu, X., and Yang, W. 2016. Pathotypes identification of Phytophthora sojae in Sichuan Province and resistance analysis of soybean germplasm. Chin. J. Oil Crop Sci. 38:539-542.

Dong, S., Qutob, D., Tedman-Jones, J., Kuflu, K., Wang, Y., Tyler, B. M., and Gijzen, M. 2009. The Phytophthora sojae avirulence locus Avr3c encodes a multi-copy RXLR effector with sequence polymorphisms among pathogen strains. PLoS One 4:e5556.

Dorrance, A. E., Berry, S. A., Anderson, T. R., and Meharg, C. 2008. Isolation, storage, pathotype characterization, and evaluation of resistance for Phytophthora sojae in soybean. Online publication. Plant Health Prog. 9:35.

Dorrance, A. E., Jia, H., and Abney, T. S. 2004. Evaluation of soybean differentials for their interaction with Phytophthora sojae. Online publication. Plant Health Prog. 5:9.

Dorrance, A. E., Kurle, J., Robertson, A. E., Bradley, C. A., Giesler, L., Wise, K., and Concibido, V. C. 2016. Pathotype diversity of Phytophthora sojae in eleven states in the United States. Plant Dis. 100:1429-1437.

Dorrance, A. E., and McClure, S. A. 2001. Beneficial effects of fungicide seed treatments for soybean cultivars with partial resistance to Phytophthora sojae. Plant Dis. 85:1063-1067.

Dorrance, A. E., McClure, S. A., and St. Martin, S. K. 2003. Effect of partial resistance on Phytophthora stem rot incidence and yield of soybean in Ohio. Plant Dis. 87:308-312.

Dorrance, A. E., Robertson, A. E., Cianzo, S., Giesler, L. J., Grau, C. R., Draper, M. A., Tenuta, A. U., and Anderson, T. R. 2009. Integrated management strategies for Phytophthora sojae combining host resistance and seed treatments. Plant Dis. 93:875-882.

Dorrance, A. E., and Schmitthenner, A. F. 2000. New sources of resistance to Phytophthora sojae in the soybean plant introductions. Plant Dis. 84: 1303-1308.

Doupnik, B. 1993. Soybean production and disease estimates 1989 to 1991. Plant Dis. 77:1170-1172.

Fan, A. Y., Wang, X. M., Fang, X. P., Wu, X. F., and Zhu, Z. D. 2009. Molecular identification of Phytophthora resistance gene in soybean cultivar Yudou 25. Acta Agron. Sin. 35:1844-1850.

Gao, H. Y., Narayanan, N. N., Ellison, L., and Bhattacharyya, M. K. 2005. Two classes of highly similar coiled coil-nucleotide binding-leucine rich repeat genes isolated from the Rpsl-k locus encode Phytophthora resistance in soybean. Mol. Plant-Microbe Interact. 18:1035-1045.

Grau, C. R., Dorrance, A. E., Bond, J., and Russin, J. S. 2004. Fungal diseases. Pages 679-763 in: Soybeans: Improvement, Production, and Uses, 3rd ed. H. R.Boerma and J. E.Specht, eds. American Society of Agronomy, Crop Science Society of America, and Soil Science Society of America, Madison, WI.

Jackson, T. A., Kirkpatrick, T. L., and Rupe, J. C. 2004. Races of Phytophthora sojae in Arkansas soybean fields and their effects on commonly grown soybean cultivars. Plant Dis. 88:345-351.

Jiang, C. J., Sugano, S., Kaga, A., Lee, S. S., Sugimoto, T., Takahashi, M., and Ishimoto, M. 2017. Evaluation of resistance to Phytophthora sojae in soybean mini core collections using an improved assay system. Phytopathology 107:216-223.

Kaufmann, M. J., and Gerdemann, J. W. 1958. Root and stem rot of soybean caused by Phytophthora sojae. Phytopathology 48:201-208.

Kilen, T. C., Hartwig, E. E., and Keeling, B. L. 1974. Inheritance of a second major gene for resistance to Phytophthora root rot in soybeans. Crop Sci. 14:260-262.

Kyle, D. E., Nickell, C. D., Nelson, R. L., and Pedersen, W. L. 1998. Response of soybean accessions from provinces in southern China to Phytophthora sojae. Plant Dis. 82:555-559.

Leitz, R. A., Hartman, G. L., Pedersen, W. L., and Nickell, C. D. 2000. Races of Phytophthora sojae on soybean in Illinois. Plant Dis. 84:487.

Li, X. N., Sun, S., Zhong, C., and Han, T. F. 2017. Resistance evaluation to eight Phytophthora sojae isolates for major soybean cultivars in Huang-Huai-Hai Rivers Valley. Acta Agron. Sin. 43:1774-1783.

Lin, F., Zhao, M., Ping, J., Johnson, A., Zhang, B., Abney, T. S., Hughes, T. J., and Ma, J. 2013. Molecular mapping of two genes conferring resistance to Phytophthora sojae in a soybean landrace PI 567139B. Theor. Appl. Genet. 126:2177-2185.

Lohnes, D. G., Nickell, C. D., and Schmitthenner, A. F. 1996. Origin of soybean alleles for Phytophthora resistance in China. Crop Sci. 36:1689-1692.
McBlain, B. A., Hacker, J. K., Zimmerly, M. M., and Schmitthenner, A. F. 1991. Tolerance to Phytophthora rot in soybean: II. Evaluation of three tolerance screening methods. Crop Sci. 31:1412-1417.

Moots, C. K., Nickell, C. D., Gray, L. E., and Lim, S. M. 1983. Reaction of soybean cultivars to 14 races of Phytophthora-megasperma f-sp-glycinea. Plant Dis. 67:764-767.

Morgan, F. L., and Hartwig, E. E. 1965. Physiologic specialization in Phytophthora megasperma var. sojae. Phytopathology 55:1277-1279.

Morris, P. F., and Ward, E. W. B. 1992. Chemoattraction of zoospores of the soybean pathogen, Phytophthora sojae, by isoflavones. Physiol. Mol. Plant Pathol. 40:17-22.

Ping, J., Fitzgerald, J. C., Zhang, C., Lin, F., Bai, Y., Wang, D., Aggarwal, R., Rehman, M., Crasta, O., and Ma, J. 2016. Identification and molecular mapping of Rps11, a novel gene conferring resistance to Phytophthora sojae in soybean. Theor. Appl. Genet. 129:445-451.

Sahoo, D. K., Abeysekara, N. S., Cianzio, S. R., Robertson, A. E., and Bhattacharyya, M. K. 2017. A novel Phytophthora sojae resistance Rps 12 gene mapped to a genomic region that contains several Rps genes. PLoS One 12:e169950.

Sandhu, D., Schallock, K. G., Rivera-Velez, N., Lundeen, P., Cianzio, S., and Bhattacharyya, M. K. 2005. Soybean Phytophthora resistance gene Rps8 maps closely to the Rps3 region. J. Hered. 96:536-541.

Schmitthenner, A. F. 1985. Problems and progress in control of Phytophthora root rot of soybean. Plant Dis. 69:362-368.

Schmitthenner, A. F., Hobe, M., and Bhat, R. G. 1994. Phytophthora sojae races in Ohio over a 10-year interval. Plant Dis. 78:269-276.

Schneider, R., Rolling, W., Song, Q., Cregan, P., Dorrance, A. E., and McHale, L. K. 2016. Genome-wide association mapping of partial resistance to Phytophthora sojae in soybean plant introductions from the Republic of Korea. BMC Genomics 17:607.

Slaminko, T. L., Bowen, C. R., and Hartman, G. L. 2010. Multi-year evaluation of commercial soybean cultivars for resistance to Phytophthora sojae. Plant Dis. 94:368-371.

Stewart, S., and Robertson, A. E. 2012. A modified method to screen for partial resistance to Phytophthora sojae in soybean. Crop Sci. 52:1181-1186.

Sugimoto, T., Kato, M., Yoshida, S., Matsumoto, I., Kobayashi, T., Kaga, A., Hajika, M., Yamamoto, R., Watanabe, K., Aino, M., Matoh, T., Walker, D. R., Biggs, A. R., and Ishimoto, M. 2012. Pathogenic diversity of Phytophthora sojae and breeding strategies to develop Phytophthora-resistant soybeans. Breed. Sci. 61:511-522.

Sun, J. T., Li, L. H., Zhao, J. M., Huang, J., Yan, Q., Xing, H., and Guo, N. 2014 Genetic analysis and fine mapping of RpsJS, a novel resistance gene to Phytophthora sojae in soybean [Glycine max (L.) Merr]. Theor. Appl. Genet. 127:913-919.

Tang, Q. H., Cui, L. K., Li, D. L., Dai, T. T., Yin, W. X., Dong, S. M., Xing, H., Zheng, X. B., and Wang, Y. C. 2010. Resistance evaluation of soybean germplasm from Huanghuai valley to Phytophthora root rot. Sci. Agric. Sin. 43:2246-2252.

Tyler, B. M. 2007. Phytophthora sojae: Root rot pathogen of soybean and model oomycete. Mol. Plant Pathol. 8:1-8.

Wagner, R. E., and Bernard, R. L. 1991. Response of Williams isolines to eight races of Phytophthora megasperma f.sp. glycinea. Soybean Genet. Newsl. 18:236-239.

Wu, X. L., Zhang, B. Q., Sun, S., Zhao, J. M., Yang, F., Guo, N., Gai, J. Y., and Xing, H. 2011. Identification, genetic analysis and mapping of resistance to Phytophthora sojae of Pm28 in soybean. Agric. Sci. China 10:1506-1511.

Yao, H. Y., Wang, X. M., Wu, X. F., Xiao, Y. N., and Zhu, Z. D. 2010. Molecular mapping of Phytophthora resistance gene in soybean cultivar Zaoshu18. J. Plant Genet. Resour. 11:213-217.

Yin, R. F., Feng, X. J., and Zhang, Z. 2017. Changes of soybean planting area in northeast China and the Huang-Huai region in 2017 and its production outlook. Agric. Outlook 7:42-47

Yu, A. L., Xu, P. F., Wang, J. S., Zhang, S. Z., Wu, J. J., Li, W. B., Chen, W. Y., Li, N. H., Fan, S. J., Wang, X., and Jiang, L. Y. 2010. Genetic analysis and SSR mapping of gene resistance to Phytophthora sojae race 1 in soybean cv Suinong 10. Chin. J. Oil Crop Sci. 32:462-466.

Zhang, J. Q., Sun, S. L., Wang, G. Q., Duan, C. X., Wang, X. M., Wu, X. F., and Zhu, Z. D. 2014. Characterization of Phytophthora resistance in soybean cultivars/lines bred in Henan province. Euphytica 196:375-384.

Zhang, J. Q., Xia, C. J., Duan, C. X., Sun, S. L., Wang, X. M., Wu, X. F., and Zhu, Z. D. 2013. Identification and candidate gene analysis of a novel Phytophthora resistance gene Rps10 in a Chinese soybean cultivar. PLoS One 8:e69799.

Zhang, S. Z., Xu, P. F., Wu, J. J., Xue, A. G., Zhang, J. X., Li, W. B., Chen, C. Chen, W. Y., and Lv, H. Y. 2010. Races of Phytophthora sojae and their virulences on soybean cultivars in Heilongjiang, China. Plant Dis. 94:87-91.

Zhu, Z. D., Huo, Y. L., Wang, X. M., Huang, J. B., and Wu, X. F. 2006. Screening for resistance sources to Phytophthora root rot in soybean. J. Plant Genet. Resour. 7:24-30.

Zhu, Z. D., Huo, Y. L., Wang, X. M., Huang, J. B., and Wu, X. F. 2007. Molecular identification of a novel Phytophthora resistance gene in soybean. Acta Agron. Sin. 33:154-157. 